\title{
Fees can serve as deterrents to Cambodian health care
}

Published at www.cmaj.ca on Oct. 22

$\mathrm{W}$ hen I went to Cambodia to work in the National Pediatric Hospital, it was to learn about HIV/AIDS, tuberculosis, malaria and dengue. While I was there, I found I learned much more about health care delivery and inequality.

In Cambodia, those who have money receive care, despite the facade of a "public" and "free" health care system. Navigating the system for families felt much the same as it does in Canada, though in Cambodia the stakes are much higher.

In Canada. I fight for MRI access; in Cambodia, I was fighting for simple access to care.

Despite the Jakarta Declaration's investment in the determinants of health, including equity and access to health care services for all, I quickly realized that these basic needs are not being guaranteed in Cambodia.

Cambodian health care is public, though many families are charged fees. This leads to an underlying distrust of the health care system. Accordingly, many families will delay visiting hospitals because of the bills they encounter and children will often come to hospital only after they have become very ill.

I saw many cases of dengue, tetanus, AIDS and tuberculosis progressing to end-stages before families thought it necessary to bring their child to hospital. It is not uncommon to hear stories of families that went seriously into debt after borrowing from loan sharks to pay for the care of family members. In fact, many families delay care for their children because they are worried about cost.

In addition, and perhaps most sadly, I saw the consequences of care being delayed even when the patient was brought to hospital in a timely manner. Typically, a family must

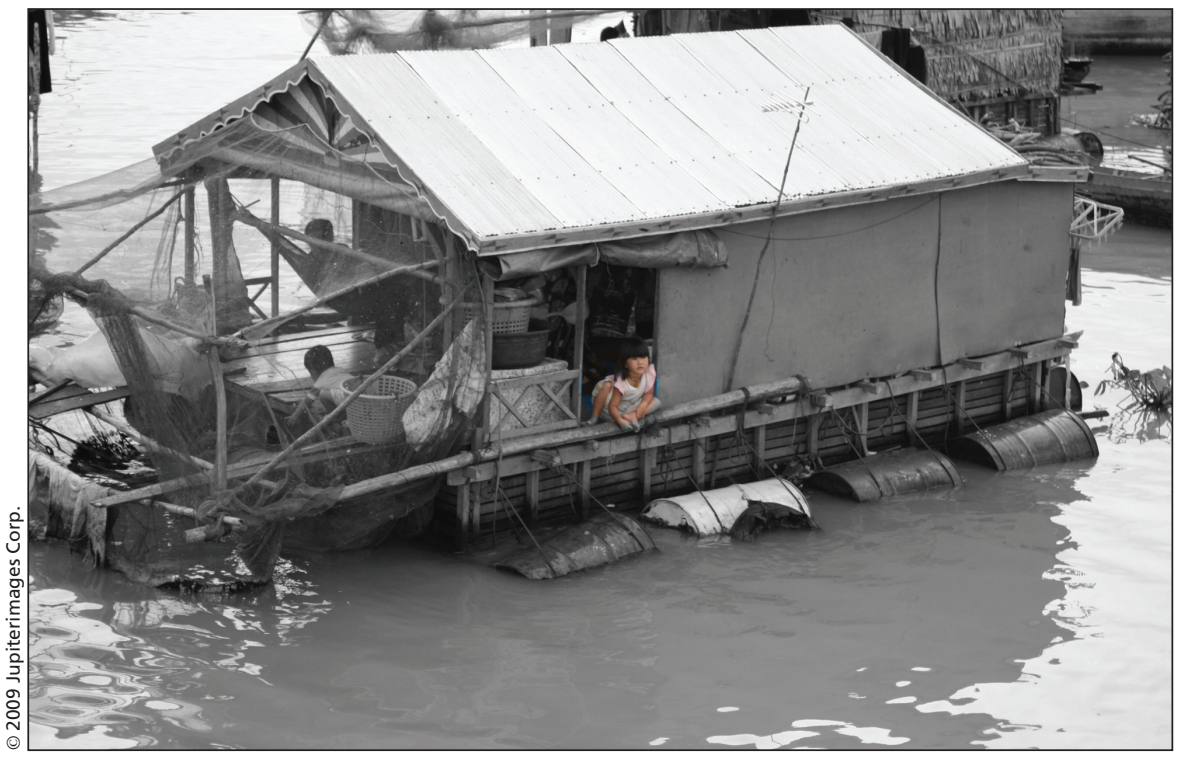

Many families delay care for their children in Cambodia because they are worried about costs, says Dr. Dina Kulik.

come up with the funds to pay for investigations and medicines, and until it does, the patient often waits without care - despite the care being "free" and seemingly accessible to all.

Most families seek the much cheaper services of pharmacists, who appear to act as Cambodia's "frontline physicians." However, the pharmacists are not trained as they are in developed countries. Therefore, it was common to see cases of overdoses, medication interactions and other medication errors. This often led to such consequences as dystonia secondary to metoclopramide prescribed for gastroenteritis and overdoses of paracetamol causing hepatotoxicity.

Nevertheless, despite inequalities of health care delivery, once care is obtained it is of good quality and provided by well-trained health care professionals. Children receive holistic, comprehensive treatment with modern medicines, procedures and investigation. The people are warm and inviting, and eager to gain knowledge and advance their practice.

Health care professionals and patients alike inspired me to continue to strive for excellence in my practice, no matter what challenges I face. Further, my work in Cambodia served as a reminder that, unfortunately, we may have a long way to go before all determinants of health are guaranteed for all children around the world. - Dina M. Kulik MD, Toronto, Ont.

DOI:10.1503/cmaj.109-3028

CMAJ invites contributions to "Dispatch from the medical front," in which physicians and other health care providers offer eyewitness glimpses of medical frontiers, whether defined by location or intervention. Submissions, which must run a maximum 700 words, should be forwarded to:wayne.kondro@cmaj.ca 